\title{
Do propranolol and amisulpride modulate confidence in risk-
}

\section{taking? [version 1; peer review: 1 approved, 1 approved with}

\section{reservations]}

\author{
Johanna Habicht ${ }^{1,2}$, Magda Dubois (iD1,2, Jochen Michely1,2, Tobias U. Hauser ${ }^{1,2}$ \\ ${ }^{1}$ Max Planck UCL Centre for Computational Psychiatry and Ageing Research, London, WC1B 5EH, UK \\ ${ }^{2}$ Wellcome Centre for Human Neuroimaging, University College London, London, WC1N 3BG, UK
}

\author{
V1 First published: 25 Jan 2022, 7:23 \\ https://doi.org/10.12688/wellcomeopenres.17423.1 \\ Latest published: 25 Jan 2022, 7:23 \\ https://doi.org/10.12688/wellcomeopenres.17423.1
}

\section{Abstract}

Background: Making rational choices and being able to consciously reflect on the goodness of these choices is important for successfully navigating the world. Value-based decisions have been extensively studied, but we know little about the factors that influence our confidence in value-based choice. Particularly, we know very little about the neurotransmitters that may mediate these processes. Methods: In this double-blind, placebo-controlled study design involving 61 healthy human subjects (30 female), we assessed the contributions of dopamine (400 mg amisulpride) and noradrenaline (40 mg propranolol) to value-based decision making and the subjective confidence therein in a monetary risky gambling task. Results: We did not find any significant effect of either of the two pharmacological manipulations, neither on value-based decision making, nor on subjective confidence.

Conclusion: We discuss these (null) findings, and release all relevant data and code. This will allow researchers to further interrogate the data, to counteract publication biases in favour of significant findings, and to use our study as a source for balanced meta-analyses.

\section{Keywords}

Value-based decision making, risk taking, confidence, catecholamines, propranolol, amisulpride

\section{Open Peer Review}

Approval Status ? 2

version 1

25 Jan 2022
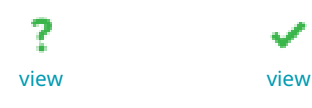

1. Marcus Grüschow ID, University of Zurich,

Zurich, Switzerland

Hui-Kuan Chung, University of Zurich,

Zurich, Switzerland

Nikita Sidorenko ID, University of Zurich,

Zurich, Switzerland

2. Laurence Hunt $[D$, University of Oxford,

Oxford, UK

Any reports and responses or comments on the article can be found at the end of the article. 
Corresponding authors: Johanna Habicht (johanna.habicht.15@ucl.ac.uk), Tobias U. Hauser (t.hauser@ucl.ac.uk)

Author roles: Habicht J: Formal Analysis, Investigation, Writing - Original Draft Preparation, Writing - Review \& Editing; Dubois M: Investigation, Writing - Review \& Editing; Michely J: Investigation, Writing - Review \& Editing; Hauser TU: Conceptualization, Formal Analysis, Supervision, Writing - Original Draft Preparation, Writing - Review \& Editing

Competing interests: No competing interests were disclosed.

Grant information: TUH is supported by a Wellcome Sir Henry Dale Fellowship [211155], a grant from the Jacobs Foundation [20171261-04], the Medical Research Foundation, a 2018 NARSAD Young Investigator grant [27023] from the Brain \& Behavior Research Foundation, a Philip Leverhulme Prize (PLP-2021-040) and a grant from the European Research Council (ERC) under the European Union's Horizon 2020 research and innovation programme (grant agreement No 946055). The Max Planck UCL Centre is a joint initiative supported by UCL and the Max Planck Society. The Wellcome Centre for Human Neuroimaging is supported by core funding from Wellcome [203147]. A CC BY or equivalent licence is applied to the Author Accepted Manuscript arising from this submission, in accordance with the grant's open access conditions.

The funders had no role in study design, data collection and analysis, decision to publish, or preparation of the manuscript.

Copyright: ( 2022 Habicht J et al. This is an open access article distributed under the terms of the Creative Commons Attribution License , which permits unrestricted use, distribution, and reproduction in any medium, provided the original work is properly cited.

How to cite this article: Habicht J, Dubois M, Michely J and Hauser TU. Do propranolol and amisulpride modulate confidence in risktaking? [version 1; peer review: 1 approved, 1 approved with reservations] Wellcome Open Research 2022, 7:23

https://doi.org/10.12688/wellcomeopenres.17423.1

First published: 25 Jan 2022, 7:23 https://doi.org/10.12688/wellcomeopenres.17423.1 


\section{Introduction}

Considering the probability and magnitude of a potential outcome is critical for adequate decision making. Over the last decades, value-based decision making has been intensively studied (Brandstätter et al., 2006; Kahneman \& Tversky, 1979; Rangel et al., 2008). Despite this wealth of research, relatively little is known about the factors that influence our conscious perception about whether such a choice was good. A feeling of confidence is important to evaluate our decisions and guide our future choices (Fleming \& Dolan, 2012). If confidence does not adequately reflect one's choice, then this can be detrimental to long-term outcomes (Rollwage et al., 2018; Rollwage et al., 2020; Schulz et al., 2020).

Such an impaired metacognition - the ability to introspect on one's own behaviour - may lead to an inaccurate view of one's own performance as seen in individuals with schizophrenia, attention-deficit/hyperactivity disorder or obsessive-compulsive symptoms (Hauser et al., 2017b; Knouse et al., 2005; Lysaker et al., 2010; Lysaker et al., 2019). These psychiatric disorders are often known to have disturbances in noradrenergic and dopaminergic systems (Faraone et al., 2015; Laruelle, 2013; Mäki-Marttunen et al., 2020), suggesting that dopamine and noradrenaline may play a role in metacognition. Indeed, in a previous study, we showed that noradrenaline plays a role in perceptual metacognition (Hauser et al., 2017a), and another study found that dopaminergic modulation impairs memory-related metacognition (Clos et al., 2019). In this study, we explore whether those findings transfer to the domain of value-based decision making.

Both dopamine and noradrenaline are also thought to play key roles in value-based decision making. Dopamine has been shown to encode expected value (Schultz, 1998; Tobler et al., 2005), modulate processing of reward magnitude and probability (Burke et al., 2018), drive choice variability (Chew et al., 2019), and influence risky options (Rigoli et al., 2016; Rutledge et al., 2015). Noradrenaline has been suggested to affect the processing of losses (Rogers et al., 2004; Sokol-Hessner et al., 2015), salience (Kahnt \& Tobler, 2013), and unexpected uncertainty (Payzan-LeNestour et al., 2013; Yu \& Dayan, 2005). Thus, in this study we additionally investigated whether we could replicate previous findings from studies using pharmacological manipulations of dopamine and noradrenaline in value-based decision making. In addition, we explored whether noradrenaline or dopamine have distinct influences on the confidence in value-based choice.

To assess the noradrenergic and dopaminergic influence on value-based decision making and confidence, we used two pharmacological manipulations in a task that was similar to a previously used task (De Martino et al., 2013). We selected drugs that are known to have a selective and high affinity for either dopamine or noradrenaline, and which have been used in studies using value-based decision making tasks (Burke et al., 2018; Jocham et al., 2011; Sokol-Hessner et al., 2015). Consequently, we used the $\beta$-adrenoceptor antagonist propranolol (40mg) for noradrenaline manipulation and the D2/D3 receptor antagonist amisulpride (400mg) for impacting dopamine functioning. In this double-blind, placebo-controlled study design (61 healthy subjects in total), we failed to find any reliable influence of amisulpride or propranolol on value-based decision making. Similarly, we did not find any association between any of the catecholamines and confidence in our task. We make all data openly available for further (meta-)analyses.

\section{Methods}

The study was conducted at University College London from January 2019 to February 2019.

\section{Participants}

We recruited 61 healthy participants aged 18-35 years ( mean $=23.28$, standard deviation $[$ s.d. $]=3.624)$ for a doubleblind, placebo-controlled, between-subjects study. The study was advertised on local subject pools, where participants could sign up on a voluntary basis. Each participant was randomly allocated to one of three groups (using randperm function in MATLAB), assuring equal gender balance in each group. The randomisation was managed by a team member who did not undertake the testing of participants. The placebo group had 21 participants, whereas the propranolol and amisulpride groups consisted of 20 participants each. The extra male participant in the placebo group was recruited due to a technical error in a different (main) task of the experiment. The sample size was selected based on previous studies that used the same pharmacological manipulation (Hauser et al., 2018; Hauser et al., 2019; Hauser et al., 2017a).

Volunteers with a history of neurological or psychiatric disorders, current health issues, regular medications (except contraceptives), or prior allergic reactions to drugs were excluded from the study. Participants were reimbursed for their participation on an hourly basis and to ensure motivation in this task, one trial was randomly selected at the end of the task and was given as a bonus payment. On average, subjects received $£ 10$ per hour.

\section{Ethical considerations}

The study was approved by the Research Ethics Committee of University College London (study number: 14261/001) and all participants provided written informed consent.

\section{Procedure}

Sixty-one healthy volunteers were randomly assigned to one of three groups: propranolol, amisulpride and placebo. The propranolol group received 40mg of propranolol, a non-selective $\beta$-adrenoceptor antagonist, while the amisulpride group was administered 400mg amisulpride, a selective D2/D3 antagonist. The placebo group did not receive any active drug. Propranolol and amisulpride have different pharmacokinetic properties and thus were administered at different times to ensure the peak effect at similar times (Figure 1A; Hauser et al., 2018; Hauser et al., 2019; Hauser et al., 2017a). Participants in amisulpride group were orally administered 400mg amisulpride to reduce dopamine functioning 140-150 minutes before the gambling task (Figure 1A). The propranolol group was orally administered 40mg propranolol to reduce noradrenaline 
functioning 30 minutes later. Each drug group received the drug on its corresponding time point and a placebo at the other time point. The placebo group received placebo at both time points, in line with our previous studies (Hauser et al., 2018; Hauser et al., 2019; Hauser et al., 2017a). The placebo used for propranolol was Vitamin D and placebo for amisulpride was Vitamin B12. Between taking the first and second drug, participants completed the WASI Matrix Reasoning subtest (Wechsler, 2013), which was used as a proxy for intellectual abilities (i.e. IQ). After 80 minutes of receiving the first drug, participants filled in the Positive and Negative Affect Schedule (PANAS) questionnaire (Watson et al., 1988) to measure their positive and negative mood. After 90 minutes of receiving the first drug, participants completed a different (main) task, reported elsewhere (Dubois et al., 2021), followed by the task presented here.

\section{Task}

The risky gambling task that participants played was set up on a computer. Participants were asked to repeatedly choose between two risky options with varying probabilities and reward magnitudes without any time limit (Figure 1B). Participants were asked to press the left arrow key to choose the option on the left and the right arrow key to choose the option on the right. The ranges of stimuli were adapted from a previously used task (Hunt et al., 2013), and they were drawn such that reward magnitude and probability were never identical across the two options. The reward magnitude ranged from $£ 1$ to $£ 9$ and the probability ranged from $10 \%$ to $90 \%$. Therefore, participants had to integrate across reward magnitude and probability to make optimal choices. Participants were presented with each combination of options $(n=54)$ twice, counterbalanced across left-right spatial configurations. After every choice, participants were asked to indicate their confidence level (i.e. "How confident are you that the choice you made was the right one for you?") on a continuous scale between 1 (low confidence) and 10 (high confidence). Participants were given $6,000 \mathrm{~ms}$ to choose their level of confidence in their decision. Every participant completed 108 trials divided in 4 blocks. They also completed 10 practice trials before starting the task to ensure their understanding of the task. It took participants up to 10 minutes to complete the task.

\section{Statistical analyses}

We compared behavioural measures using one-way ANOVAs with drug group as between-subject factor (placebo, propranolol, amisulpride). We further compared the measures using ANCOVAs with drug group as between-subject factor and controlling for intellectual abilities (WASI score) and positive and negative affect (PANAS scores). Significant effects were further explored using (independent samples) t-tests. We report effect sizes using partial eta squared $\left(\eta^{2}\right)$ for ANOVAs and Cohen's d (d) for t-tests. The analyses were conducted in MATLAB (R2020a) (open alternative: GNU Octave) and SPSS software (version 26, IBM).

To support the null-hypotheses further, we conducted Bayesian ANOVAs and Bayesian ANCOVAs using JASP software (Version 0.14.1). We use Bayes Factor 01 (BF01) to report evidence in favour of the null hypothesis.

\section{Results}

Procedure

To examine the role of catecholamines in value-based choice and confidence, we ran a double-blind, placebo-controlled, between-subjects study. We excluded four participants from the main analysis. Two participants were excluded due to poor
A

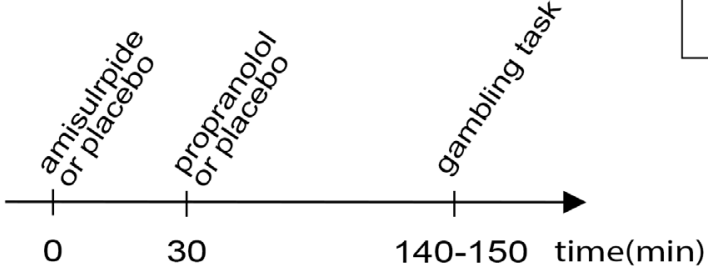

B

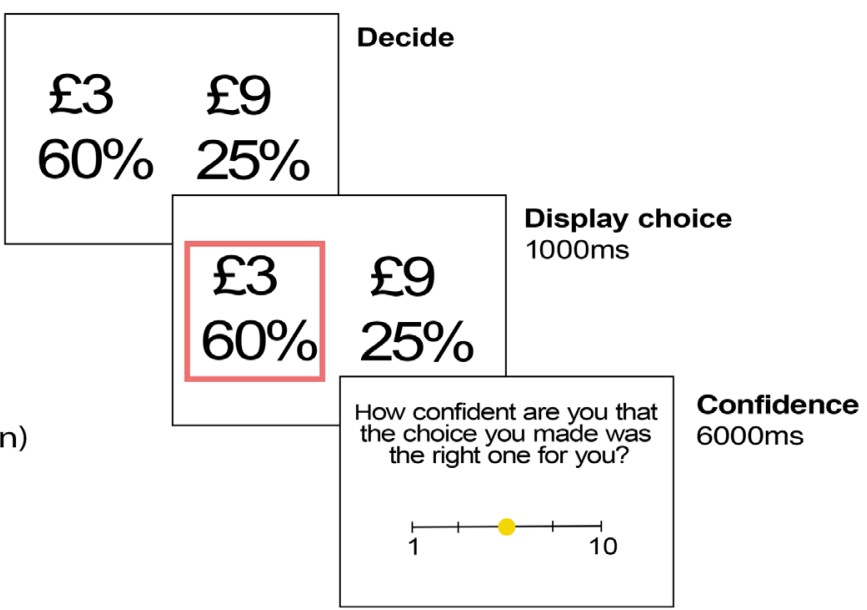

Figure 1. Study design and task procedure. (A) Before completing the task, participants were administered drugs: either amisulpride which blocks dopaminergic D2/D3 receptors, propranolol that blocks noradrenergic $\beta$-receptors or inert substances for placebo group. Different administration times were chosen to ensure the peak effect at similar times as the drugs have different pharmacokinetic properties. (B) Participants were presented with two choice options with varying reward and probability, and had to choose one. After each choice, they were asked their level of confidence for choosing the best option. Participants did not see the outcome of the gamble, but they were instructed that one of the gambles will be chosen randomly to win a bonus in the end of the task. 
performance as seen in the low proportions of choosing the option with higher reward magnitude and probability in 'no-brainer' trials $(67.5 \%$ and $55 \%$, while the mean of the other subjects was at $98.1 \%$, s.d. $=3.169$; the excluded participants were from amisulpride and placebo group respectively, both female). Additional two participants were excluded (1 male from placebo group, 1 female from propranolol group) due to perfect choice patterns that prevented reliable estimation of a logistic fit, leaving nineteen participants to each group (c.f. Table 1). Because our final drug groups differed marginally in IQ and positive and negative mood (cf. methods for details), we decided to report all findings with and without controlling for these covariates.

All volunteers played a version of a monetary risky gambling task (Figure 1B). They were asked to make repeated choices between two choice options with varying probabilities and reward magnitudes (e.g., $60 \%$ of chance of receiving $£ 3$ vs $25 \%$ chance of receiving $£ 9$ ). The ranges of stimuli were adapted from a previously used task (Hunt et al., 2013). From here on, we refer to the monetary amount as 'reward magnitude', the probability of receiving the monetary amount as 'probability', and to the multiple of the amount of money and probability as 'expected value' (EV). After every choice, participants reported their confidence from a scale of 1 to 10 , which reflects the degree of subjective certainty that they had in making the best choice for themselves (De Martino et al., 2013). Subjects never saw the outcome of their choice.

\section{Similar performance between groups}

Before investigating the role of noradrenaline and dopamine in value-based decisions and confidence, we were interested in assessing whether the groups performed similarly in the simplest performance metrics of the task. Firstly, we examined 'no-brainer' trials, in which both reward magnitude and probability of one choice option were higher than that of the other, thus suggesting that one should pick the option with higher reward magnitude and probability. There were no differences between groups in these 'no-brainer' trials $(F(2,54)=1.31$, $p=0.279, \eta^{2}=0.046$; controlling for IQ and positive and negative mood: $\left.F(2,51)=2.00, p=0.146, \eta^{2}=0.073\right)$. Reassuringly, there was a significant effect of IQ on no-brainer trials $\left(\mathrm{F}(1,51)=7.30, \mathrm{p}=0.009, \eta^{2}=0.125\right)$.

Next, we looked at the proportion of trials where individuals chose the optimal option, i.e. the option with higher EV (all participants: mean $=57.6 \%$, s.d. $=2.854)$. We did not find any group differences $\left(F(2,54)=0.36, p=0.700, \eta^{2}=0.013\right.$; controlling for covariates: $F(2,51)=0.30, p=0.744, \eta^{2}=0.012$ ). Using Bayesian statistics, we found moderate evidence that the null model (i.e. no difference) is 5 times more likely $(B F 01=5.51)$ than a model that distinguishes between groups, suggesting that groups did not behave differently in choosing optimal options. When further controlling for covariates, we found strong evidence for no difference between groups $(B F O 1=99.5)$.

Furthermore, we did not find any group differences in reaction times of the choice $\left(F(2,54)=0.75, p=0.478, \eta^{2}=0.027\right.$; controlling for covariates: $\left.F(2,51)=1.07, p=0.351, \eta^{2}=0.040\right)$. These findings thus allow us to compare value-based decisions between groups without having to account for basic performance biases.

\section{How do reward magnitude, probability and EV predict} choice?

In gambles like these, the optimal strategy would be to calculate the expected value (EV) of each option and chose the one with the higher EV. However, humans most often act sub-optimally, with a substantial proportion of subjects being more strongly influenced by either probability or magnitude, rather than their product.

To evaluate the influence that reward magnitude, probability and EV had on participants' choices, we thus followed a similar analysis to Hunt and colleagues (Hunt et al., 2013). We performed a logistic regression to predict choosing the option on the right side at every trial using reward magnitude, probability

Table 1. The drug groups did not differ in gender, nor in age. The final groups differed marginally in intellectual abilities (adapted WASI matrix test), and positive and negative affect score from PANAS questionnaire, which is why we chose to control for these covariates and report effects with and without controlling for them.

\begin{tabular}{|c|c|c|c|c|}
\hline & Propranolol & Placebo & Amisulpride & \\
\hline Gender (F/M) & $9 / 10$ & $9 / 10$ & $9 / 10$ & \\
\hline Age & $22.95(3.628)$ & $23.84(4.259)$ & 23.05 (3.009) & $\begin{array}{c}F(2,54)=0.338, p=0.715 \\
\eta 2=0.012\end{array}$ \\
\hline Intellectual abilities & $22.84(1.893)$ & $22.47(3.762)$ & $24.37(2.454)$ & $\begin{array}{c}F(2,54)=2.421, p=0.098 \\
\eta 2=0.082\end{array}$ \\
\hline Positive affect & $23.63(8.214)$ & $27.74(5.896)$ & $29.58(10.205)$ & $\begin{array}{c}F(2,54)=2.560, p=0.087 \\
\eta 2=0.087\end{array}$ \\
\hline Negative affect & $10.68(0.820)$ & $12.21(2.780)$ & $11.16(1.708)$ & $\begin{array}{c}F(2,54)=3.073, p=0.054 \\
\eta 2=0.102\end{array}$ \\
\hline
\end{tabular}


and EV as predictors (Figure 2A). A significant effect of reward magnitude $(t(56)=4.97, p<0.001)$, probability $(t(56)=8.72$, $p<0.001)$ and $\operatorname{EV}(t(56)=5.98, p<0.001)$ indicated that the participants took all the factors (separately and combined) into account when making a decision. We found that the intercept did not have any effect on predicting the choice $(t(56)=1.36$, $p=0.180$ ), showing that there were no spatial choice biases predicting the choice similar to Hunt et al.'s findings (Hunt et al., 2013).

\section{No drug effects on how reward magnitude, probability} and EV affect choice

To examine whether catecholamines affect how the reward magnitude, probability and EV influence one's choice, we compared the parameter estimates from the logistic regression between groups (Figure 2B). There were marginal differences in how the reward magnitude influenced choice between groups $\left(F(2,54)=2.71, p=0.075, \eta^{2}=0.091\right)$, however this difference disappeared when controlling for further IQ and $\operatorname{mood}\left(F(2,51)=1.92, p=0.157, \eta^{2}=0.070\right)$. In addition, there were marginal differences in how probability affects choice $\left(F(2,54)=2.64, p=0.081, \eta^{2}=0.089\right)$, but this difference was no longer present when adding the covariates $(F(2,51)=1.75$, $\left.p=0.184, \eta^{2}=0.064\right)$. Finally, we did not find any differences in how $\mathrm{EV}$ affects choice between groups $(F(2,54)=1.62$, $p=0.208, \eta^{2}=0.057$; controlling for covariates: $F(2,51)=0.81$, $\left.p=0.452, \eta^{2}=0.031\right)$.

We found no evidence that the null model is more likely than a model that distinguishes between groups for both magnitude and probability (reward magnitude: $\mathrm{BF} 01=1.01$; probability: $\mathrm{BF} 01=1.06 ; \mathrm{EV}: \mathrm{BF} 01=2.21$, however when further controlling for the covariates we found a moderate evidence for the support of null model (reward magnitude: BF01 = 13.65; probability: $\mathrm{BF} 01=5.13$; $\mathrm{EV}: \mathrm{BF} 01=8.32$ ). These results suggest that in our sample, the catecholamines had little to no role in how participants used reward magnitude, probability, and EV to guide one's choice.

\section{Proportion of chosen uncertain options is similar between groups}

Noradrenaline has been suggested to be linked to uncertainty processing (Yu \& Dayan, 2005), thus we investigated whether there were any differences in how groups chose options with higher uncertainty. To measure uncertainty preference, we investigated the proportion of choices in which participants chose the option that had a probability that was closer to $50 \%$ (excluding trials with the same distance from 50\%). This metric captures how willing you are to make a choice that is uncertain, as $50 \%$ is the most uncertain of all options.

We found marginal differences between the groups $(F(2,54)=$ $\left.3.17, p=0.050, \eta^{2}=0.105\right)$, primarily because the propranolol group was less likely to choose these uncertain options (placebo vs propranolol group: $t(36)=2.36, p=0.024$, placebo vs amisulpride group: $t(36)=1.05, p=0.268$, propranolol vs amisulpride group: $t(36)=-1.50, p=0.143$ ). However, when controlling for further covariates, the drug effect no longer remained significant $\left(F(2,51)=1.23, p=0.300, \eta^{2}=0.046\right)$, suggesting the effect could be explained (in part) by the difference in negative $\operatorname{mood}\left(\mathrm{F}(1,51)=5.68, \mathrm{p}=0.021, \eta^{2}=0.100\right)$, rather than by the noradrenergic manipulation, as lower negative mood was associated with less uncertain options are chosen. However, when further exploring this effect, we found that the null hypothesis (no difference) was not more likely than the drug group model

A

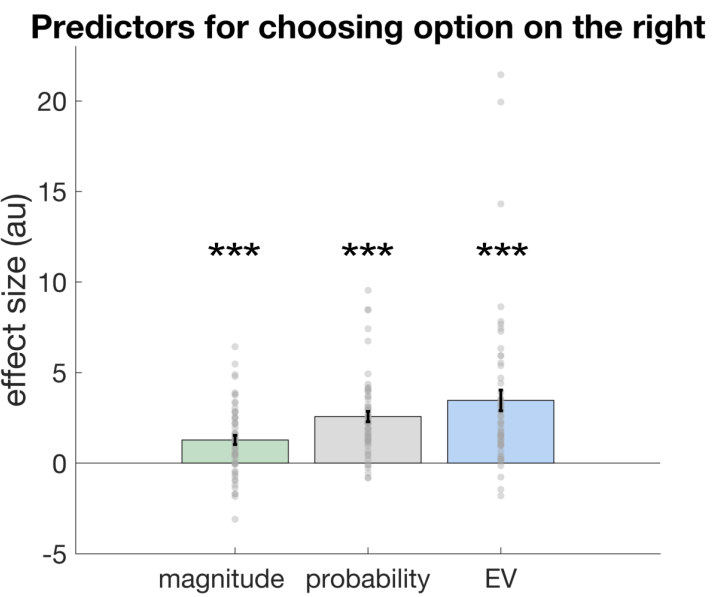

B

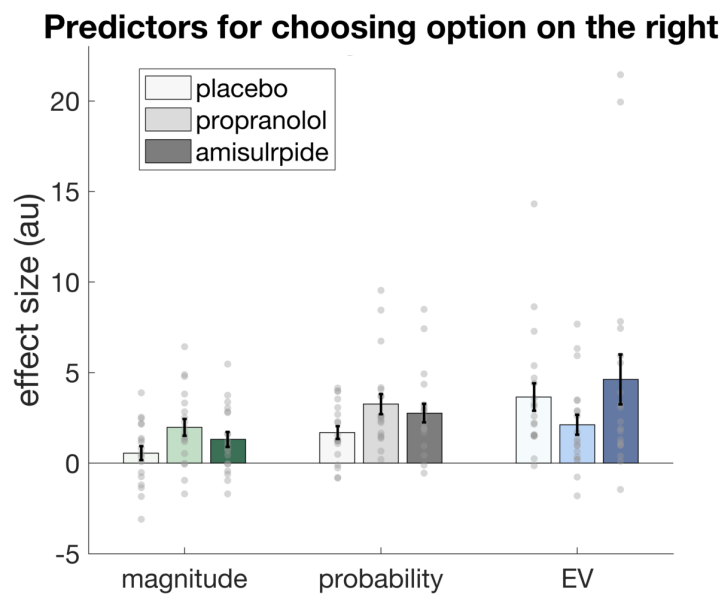

Figure 2. Factors governing risky choice. (A) Group analysis of 57 participants shows that the choice was predicted by factors of reward magnitude, probability and expected value (EV) demonstrating that subjects successfully took all the factors into account when making a decision. (B) There were no differences between groups in how reward magnitude, probability and EV predicted choice. Bar plots indicate mean \pm 1 SEM; $* * * ~ p<.001 ;$ au, arbitrary units. 
$(B F 01=0.73$; controlling for covariates: $B F 01=0.88)$, thus there was no conclusive evidence for the group differences in choosing uncertain options.

\section{No drug effects on biases in confidence reporting}

Next, we examined whether drugs affected the overall confidence level. We excluded one extra participant from the confidence level analysis due to having more than $90 \%$ of identical responses (male from amisulpride group). We found no differences between groups in the mean confidence level $(F(2,51)=0.026, p=0.974$, $\eta^{2}=0.001$; controlling for covariates: $F(2,48)=0.056, p=0.956$, $\eta^{2}=0.002$ ). To ensure that one group was not more random in reporting their confidence, we analysed the variability of the participants' reports (s.d. of the reported confidence) and did not observe any drug effects $(F(2,51)=0.13, p=0.875$, $\eta^{2}=0.005$; controlling for covariates: $F(2,48)=0.38, p=0.686$, $\left.\eta^{2}=0.016\right)$. There were no differences in the time taken to report confidence between groups $(F(2,53)=0.36, p=0.703$, $\eta^{2}=0.014$; controlling for covariates: $F(2,48)=0.21, p=0.812$, $\left.\eta^{2}=0.009\right)$. Thus, these findings suggest that there is no drug-related overall bias in the confidence reports.

\section{Expected value and confidence}

Next, we were interested in how the confidence reports relate to the relevant task variables. Optimally, confidence should reflect the (absolute) EV difference between the options, because this signifies the difficulty of a choice. However, absolute EV difference accounted on average only for $10.4 \%$ of the confidence variance (mean correlation between confidence and EV difference: $r=0.32$, s.d $=0.170$ ), suggesting that confidence (similarly to value-based choice above) does not solely rely on the objectively optimal criterion, EV.

To further evaluate other factors that affect confidence we fit a linear regression predicting the level of confidence using the EV difference and the chosen EV as predictors. The chosen EV is important because it reflects the overall goodness of the choice as it takes into account the total monetary amount that could be won and the probability of the chosen option. We found that both predicted the confidence level (EV difference: mean $=0.32$, s.d. $=0.235, t(55)=10.6, p<0.001$; chosen EV: mean $=0.13$, s.d. $=0.200, t(55)=4.81, p<0.001)$, suggesting that both factors are important in predicting confidence.

Next, we compared both predictors between groups to explore the drug effects on the confidence level predictors. We did not find any differences between groups in how the chosen EV influenced confidence $\left(F(2,53)=0.16, p=0.856, \eta^{2}=0.006\right.$; controlling for covariates: $\left.F(2,50)=0.32, p=0.727, \eta^{2}=0.013\right)$. There was moderate evidence that the null model is more likely compared to model that distinguishes between groups $(B F 01=3.18)$, and strong evidence for null model when further controlling for covariates $(B F 01=16.92)$.

Likewise, we did not find any differences between groups in how the EV difference influenced confidence $(F(2,53)=0.98$, $p=0.382, \eta^{2}=0.036$; controlling for IQ and negative mood: $\left.F(2,50)=0.32, p=0.731, \eta^{2}=0.012\right)$. We found moderate evidence towards null hypothesis $(B F 01=6.07)$, and strong evidence supporting null model when controlling for covariates $(B F 01=72.66)$. These findings suggest that in our sample EV difference and chosen EV affected confidence similarly between groups.

\section{Choice and confidence consistency}

In this task, each item pairing was repeated twice (once in each spatial configuration), and therefore it was possible to examine choice consistency by investigating the chosen option at both times when the same item pairing was presented. On average only $13.2 \%$ (s.d. $=8.26 \%$ ) of choices were reversed on the second encounter, showing that participants were consistent in their choices. To explore whether there were any drug effects on choice consistency in the context of this task, we compared the consistency between groups. We did not find any differences between groups $\left(F(2,54)=0.22, p=0.801, \eta^{2}=0.008\right.$; controlling for covariates: $\left.F(2,51)=1.42, p=0.252, \eta^{2}=0.053\right)$.

Interestingly, choices that would be subsequently reversed were associated with lower confidence in the first trial (reversal confidence: mean $=63.4$, s.d $=18.54$; repetition confidence: mean $=81.0$, s. $d .=10.22 ; t(57)=8.60, p<0.001)$, confirming that lower confidence is associated with changes of mind (Moses-Payne et al., 2021; Rollwage et al., 2020). There were no differences between groups (confidence main effect: $F(1,53)=76.35, p<0.001, \eta^{2}=0.590$, drug main effect: $\mathrm{F}(2,53)=0.094, \mathrm{p}=0.911, \eta^{2}=0.004$, confidence and drug interaction: $F(2,53)=0.003, p=0.0997, \eta^{2}=0.590$; controlling for covariates: drug main effect: $\mathrm{F}(2,50)=0.069, \mathrm{p}=0.934$, $\eta^{2}=0.003$, confidence and drug interaction: $F(2,50)=0.168$, $\left.p=0.846, \eta^{2}=0.007\right)$. These findings thus suggest that confidence reports were meaningfully linked to task relevant variables and subsequent behaviour, but we did not observe any drug-induced changes in the utilisation of confidence.

\section{Discussion}

Making rational choices and being able to consciously reflect on the goodness of these choices is important for successfully navigating the world. Previously, it has been proposed that dopamine and noradrenaline play a role in how reward magnitude and probability are perceived and integrated (Burke et al., 2018; Jocham et al., 2011; Rogers et al., 2004). In our study, the two pharmacological manipulations we used to target noradrenaline ( $\beta$-adrenoceptor antagonist propranolol) and dopamine (D2/D3 receptor antagonist amisulpride) did not have a reliably significant effect on value-based decision making. Furthermore, we did not find any influence of noradrenaline or dopamine manipulation in the subjective confidence in one's choice.

We did not find any differences between groups in how participants chose more optimal options (i.e. options with higher expected value), thus not replicating findings by Burke and colleagues (Burke et al., 2018). Their findings suggested that participants who received the same dose of amisulpride (400mg) chose more expected value options (Burke et al., 2018) than those who received a placebo. This may be due to their study's substantially bigger sample size (placebo group $(n=48)$ and 
amisulpride group $(\mathrm{n}=45))$ that allowed to detect smaller effect sizes. A further difference is that the task used by Burke and colleagues only had 20 trials per person, using an adaptive task structure that adjusted each trial according to participants' risk attitude. The task additionally included potential losses as choice options. Thus, the differences in the task structures or our smaller sample size may have accounted for the lack of replication of their findings.

Our findings suggest that participants use information about the reward magnitude and probability to guide their choice, replicating findings by Hunt and colleagues (Hunt et al., 2013) in a similar task. We did not find any drug effects on how reward magnitude and probability are integrated to the choice. Previously, pharmacological dopamine manipulations have found that dopamine plays a role in value-based decision making, including modulation of how reward magnitude and probability are processed after amisulpride administration (Burke et al., 2018). The lack of findings here may be due to the difference in the task structures or lower sample size compared to the study by Burke and colleagues (Burke et al., 2018) as mentioned above.

We observed that confidence is influenced by the overall goodness of the choice (i.e. potential overall outcome), as well as the difference in expected value between options (i.e. choice difficulty). Furthermore, we found that choices that had lower confidence were associated with changes of mind suggesting that confidence is useful in trying a different option when the previous choice did not have the expected consequence. We did not find any influence of amisulpride nor propranolol in the construction of confidence ratings, suggesting that dopamine and noradrenaline did not play a role in confidence in this task context.

There are several limitations of this study that need to be considered here. Firstly, we had a relatively small sample size, substantially smaller than other drug studies (Burke et al., 2018). We based our sample size on previous studies, which found reliable drug effects using similar sample sizes (De Martino et al., 2008; Dubois et al., 2021; Gibbs et al., 2007; Hauser et al., 2017a; Hauser et al., 2018; Hauser et al., 2019;
Kahnt \& Tobler, 2017). This suggests that the effect sizes of the drugs may be smaller on this task compared to the other tasks. In addition, our drug groups (marginally) differed in mood and IQ. By controlling for these covariates, we may have further decreased the effect sizes as we controlled for shared variance between the drug groups and the covariates. Lastly, we believe it is unlikely that our drug dosages were ineffective as previous studies have found neurocognitive effects with the same doses (Burke et al., 2018; Hauser et al., 2018; Hauser et al., 2019; Hauser et al., 2017a; Kahnt et al., 2015; Kahnt \& Tobler, 2017).

In conclusion, we did not find sufficient evidence that amisulpride and propranolol affected value-based decision making or the confidence in one's choice in the context of this study. We report these results here together with the release of all relevant data and code. This will allow researchers to further interrogate the data, to counteract publication biases in favour of significant findings, and to use our study as a source for balanced meta-analyses.

\section{Data availability}

Underlying data

Zenodo: DevComPsy/NaDa-Gamflidence: NaDa Gamflidence Data and Code. https://doi.org/10.5281/zenodo.5727351 (Habicht, 2021).

This project contains the following underlying data:

- all_data_in_one_table_anonymised.csv

- anonymised demographics.csv

\section{Extended data}

Analysis and task code available from: https:/github.com/ DevComPsy/NaDa-Gamflidence/tree/v1.1

Archived analysis and task code at time of publication: https://doi.org/10.5281/zenodo.5727351 (Habicht, 2021)

Data are available under the terms of the Creative Commons Attribution 4.0 International license (CC-BY 4.0).
Brandstätter E, Gigerenzer G, Hertwig R: The priority heuristic: Making choices without trade-offs. Psychol Rev. 2006; 113(2): 409-32. PubMed Abstract | Publisher Full Text | Free Full Text Burke CJ, Soutschek A, Weber S, et al.: Dopamine Receptor-Specific Contributions to the Computation of Value. Neuropsychopharmacology. 2018; 43(6): 1415-1424.

PubMed Abstract | Publisher Full Text | Free Full Text

Chew B, Hauser TU, Papoutsi M, et al.: Endogenous fluctuations in the dopaminergic midbrain drive behavioral choice variability. Proc Natl Acad Sci U S A. 2019; 116(37): 18732-18737.

PubMed Abstract | Publisher Full Text | Free Full Text

Clos M, Bunzeck N, Sommer T: Dopamine is a double-edged sword: dopaminergic modulation enhances memory retrieval performance but impairs metacognition. Neuropsychopharmacology. 2019; 44(3): 555-563. PubMed Abstract | Publisher Full Text | Free Full Text

De Martino B, Fleming SM, Garrett N, et al:: Confidence in value-based choice. Nat Neurosci. 2013; 16(1): 105-10.

PubMed Abstract | Publisher Full Text | Free Full Text

De Martino B, Strange BA, Dolan RJ: Noradrenergic neuromodulation of human attention for emotional and neutral stimuli. Psychopharmacology (Berl). 2008; 197(1): 127-136.

PubMed Abstract | Publisher Full Text | Free Full Text

Dubois M, Habicht J, Michely J, et al.: Human complex exploration strategies are enriched by noradrenaline-modulated heuristics. Elife. 2021; 10: e59907. PubMed Abstract | Publisher Full Text | Free Full Text

Faraone SV, Asherson P, Banaschewski T, et al.: Attention-deficit/hyperactivity 
disorder. Nat Rev Dis Primers. 2015; 1: 15020.

PubMed Abstract | Publisher Full Text

Fleming SM, Dolan RJ: The neural basis of metacognitive ability. In Philos Trans R Soc Lond B Biol Sci. 2012; 367(1594): 1338-49. PubMed Abstract | Publisher Full Text | Free Full Text

Gibbs AA, Naudts KH, Spencer EP, et al.: The role of dopamine in attentional and memory biases for emotional information. Am J Psychiatry. 2007; 164(10): 1603-1609.

PubMed Abstract | Publisher Full Text

Habicht J: DevComPsy/NaDa-Gamflidence: NaDa Gamflidence Data and Code (v1.1). Zenodo. 2021.

http://www.doi.org/10.5281/zenodo.572735

Hauser TU, Allen M, Purg N, et al.: Noradrenaline blockade specifically enhances metacognitive performance. Elife. 2017a; 6: e24901.

PubMed Abstract | Publisher Full Text | Free Full Text

Hauser TU, Allen M, Rees G, et al:: Metacognitive impairments extend perceptual decision making weaknesses in compulsivity. Sci Rep. 2017b; 7(1): 6614

PubMed Abstract | Publisher Full Text | Free Full Text

Hauser TU, Eldar E, Purg N, et al.: Distinct Roles of Dopamine and Noradrenaline in Incidental Memory. J Neurosci. 2019; 39(39): 7715-7721. PubMed Abstract | Publisher Full Text | Free Full Text

Hauser TU, Moutoussis M, Purg N, et al.: Beta-blocker propranolol modulates decision urgency during sequential information gathering. J Neurosci. 2018 38(32): 7170-7178.

PubMed Abstract | Publisher Full Text | Free Full Text

Hunt LT, Woolrich MW, Rushworth MF, et al.: Trial-Type Dependent Frames

of Reference for Value Comparison. PLoS Comput Biol. 2013; 9(9): e1003225.

PubMed Abstract | Publisher Full Text | Free Full Text

Jocham G, Klein TA, Ullsperger M: Dopamine-mediated reinforcement learning signals in the striatum and ventromedial prefrontal cortex underlie value-based choices. J Neurosci. 2011; 31(5): 1606-13.

PubMed Abstract | Publisher Full Text | Free Full Text

Kahneman D, Tversky A: Prospect Theory: An Analysis of Decision unde

Risk. Econometrica. 1979; 47(2): 263-292.

Publisher Full Text

Kahnt T, Tobler PN: Salience signals in the right temporoparietal junction facilitate value-based decisions. J Neurosci. 2013; 33(3): 863-9.

PubMed Abstract | Publisher Full Text | Free Full Text

Kahnt T, Tobler PN: Dopamine Modulates the Functional Organization of the Orbitofrontal Cortex. J Neurosci. 2017; 37(6): 1493-1504.

PubMed Abstract | Publisher Full Text | Free Full Text

Kahnt T, Weber SC, Haker H, et al:: Dopamine D2-receptor blockade enhances decoding of prefrontal signals in humans. J Neurosci. 2015; 35(9): 4104-11. PubMed Abstract | Publisher Full Text | Free Full Text

Knouse LE, Bagwell CL, Barkley RA, et al: Accuracy of self-evaluation in adults with ADHD: Evidence from a driving study. J Atten Disord. 2005; 8(4): 221-34. PubMed Abstract | Publisher Full Text

Laruelle M: The second revision of the dopamine theory of schizophrenia: Implications for treatment and drug development. Biol Psychiatry. 2013;

74(2): 80-1.

PubMed Abstract | Publisher Full Text

Lysaker PH, Dimaggio G, Carcione A, et al.: Metacognition and schizophrenia: The capacity for self-reflectivity as a predictor for prospective assessments of work performance over six months. Schizophr Res. 2010; 122(1-3): 124-30. PubMed Abstract | Publisher Full Text

Lysaker PH, Gagen E, Wright A, et al.: Metacognitive Deficits Predict Impaired Insight in Schizophrenia Across Symptom Profiles: A Latent Class Analysis.
Schizophr Bull. 2019; 45(1): 48-56.

PubMed Abstract | Publisher Full Text | Free Full Text

Mäki-Marttunen V, Andreassen OA, Espeseth $\mathrm{T}$ : The role of norepinephrine in the pathophysiology of schizophrenia. Neurosci Biobehav Rev. 2020;

118: 298-314.

PubMed Abstract | Publisher Full Text

Moses-Payne ME, Habicht J, Bowler A, et al.: I know better! Emerging metacognition allows adolescents to ignore false advice. Dev Sci. 2021 24(5): e13101.

PubMed Abstract | Publisher Full Text | Free Full Text

Payzan-LeNestour E, Dunne S, Bossaerts P, et al.: The Neural Representation of Unexpected Uncertainty during Value-Based Decision Making. Neuron. 2013; 79(1): 191-201.

PubMed Abstract | Publisher Full Text | Free Full Text

Rangel A, Camerer C, Montague PR: A framework for studying the neurobiology of value-based decision making. Nat Rev Neurosci. 2008; 9(7): 545-56.

PubMed Abstract | Publisher Full Text | Free Full Text

Rigoli F, Rutledge RB, Chew B, et al.: Dopamine increases a valueindependent gambling propensity. Neuropsychopharmacology. 2016; 41(11): $2658-67$.

PubMed Abstract | Publisher Full Text | Free Full Text

Rogers RD, Lancaster M, Wakeley J, et al.: Effects of beta-adrenocepto blockade on components of human decision-making. Psychopharmacology (Berl). 2004; 172(2): 157-64

PubMed Abstract | Publisher Full Text

Rollwage M, Dolan RJ, Fleming SM: Metacognitive Failure as a Feature of

Those Holding Radical Beliefs. Curr Biol. 2018: 28(24): 4014-4021.e8. PubMed Abstract | Publisher Full Text | Free Full Text

Rollwage $\mathrm{M}$, Loosen $\mathrm{A}$, Hauser TU, et al.: Confidence drives a neural confirmation bias. Nat Commun. 2020; 11(1): 2634.

PubMed Abstract | Publisher Full Text | Free Full Text

Rutledge RB, Skandali N, Dayan P, et al.: Dopaminergic modulation of decision making and subjective well-being. J Neurosci. 2015; 35(27): 9811-22. PubMed Abstract | Publisher Full Text | Free Full Text

Schultz W: Predictive reward signal of dopamine neurons. J Neurophysiol. 1998; 80(1): 1-27.

PubMed Abstract | Publisher Full Text

Schulz L, Rollwage M, Dolan RJ, et al.: Dogmatism manifests in lowered information search under uncertainty. Proc Natl Acad Sci U SA. 2020; 117(49): 31527-31534.

PubMed Abstract | Publisher Full Text | Free Full Text

Sokol-Hessner P, Lackovic SF, Tobe RH, et al.: Determinants of Propranolol's Selective Effect on Loss Aversion. Psychol Sci. 2015; 26(7): 1123-30. PubMed Abstract | Publisher Full Text | Free Full Text

Tobler PN, Fiorillo CD, Schultz W: Adaptive coding of reward value by dopamine neurons. Science. 2005; 307(5715): 1642-5.

PubMed Abstract | Publisher Full Text

Watson D, Clark LA, Tellegen A: Development and Validation of Brief Measures of Positive and Negative Affect: The PANAS Scales. J Pers Soc Psychol. 1988; 54(6): 1063-70.

PubMed Abstract | Publisher Full Text

Wechsler D: Review of the Wechsler Abbreviated Scale of Intelligence, Second Edition (WASI-II). J Psychoeduc Assess. 2013; 31(3): 337-341. Publisher Full Text

Yu AJ, Dayan P: Uncertainty, neuromodulation, and attention. Neuron. 2005. 46(4): 681-92.

PubMed Abstract | Publisher Full Text 


\section{Open Peer Review}

\section{Current Peer Review Status:}

\section{Version 1}

Reviewer Report 09 March 2022

https://doi.org/10.21956/wellcomeopenres.19264.r48271

(C) 2022 Hunt L. This is an open access peer review report distributed under the terms of the Creative Commons Attribution License, which permits unrestricted use, distribution, and reproduction in any medium, provided the original work is properly cited.

\section{Laurence Hunt}

Wellcome Centre for Integrative Neuroimaging, Department of Psychiatry, University of Oxford, Oxford, UK

This is a well-designed and clearly presented set of findings on the (absence of) any effects on propanolol and amisulpride on a risky decision making task with confidence ratings. It is a valuable contribution to the literature to have these null results reported and to make the data/analysis code freely available. The analyses have been performed appropriately and it is particularly sensible to see the use of Bayes factors to test for the strength of evidence in favour of the null hypothesis.

There are a couple of other features of behaviour that might be worth examining, with regards to how subjects combine probability and magnitude on the task; these may be worth further examination, if the authors have not already done so.

Firstly, in my previous work (Hunt et al., 20121 , 2013²), subjects' choices were noticeably better predicted by a model that used a Prospect theory model to integrate probabilities and magnitudes rather than just using the raw magnitudes, probabilities and EVs; there were also (mild) effects of the previous trial's outcome on the shape of the Prospect theory function (see section 4.1 in ' Modelling human decision under risk and uncertainty' for more detailed discussion). Is this also true in the current data? Can the authors also rule out that propanolol/amisulpride have any effects on group prospect theory parameters (either the main effect, or the effect of previous trial outcome on these parameters)?

Secondly, It looks from figure 2 that there may be an increased tendency for participants receiving propanolol to use an "additive" strategy to guide choice, rather than a "multiplicative" strategy (more weighting on probability/magnitude separately, rather than expected value). This could potentially be tested by looking for an interaction effect in the ANOVA (which currently only examines the main effect of drug group on EV, prob, mag, as I understand it?). Or alternatively, it might be possible to perform a model comparison to ask whether these groups have their choices best explained by a model that only includes the multiplicative terms, or just the additive terms, or 
both (as in the present model). It would be interesting (albeit a post-hoc exploratory analysis) if more subjects from the propanolol group fell into a category of choosing the option based on an additive strategy alone. (For example, one way in which this could be explained is that subjects are actually focussing on a single within-dimension comparison on each trial, which averages over many trials to appear like an additive weighting?).

Thirdly, although there is no main group difference in reaction times between the groups, it would be interesting to know whether there is any difference between the groups in terms of the relationship between value and RTs. There have been some suggestions that dopamine plays a role in motivating faster reaction times at least in very simple motivational tasks (e.g. Muhammed et al., $2016^{3}$ ), and so it would be interesting to know whether the effects of value on RT are similar across all the groups in this paradigm as well.

As a final comment, it might also be helpful if the GitHub repository has a little more documentation added on the landing page (Readme.md), to point the user in the direction of which scripts they would need to use to 'get started' with the data and reproduce the analyses shown in the paper. At the moment it is only two lines of text, and it would be a bit difficult to know quite where to begin when faced with this data/code.

\section{References}

1. Hunt LT, Kolling N, Soltani A, Woolrich MW, et al.: Mechanisms underlying cortical activity during value-guided choice.Nat Neurosci. 2012; 15 (3): 470-6, S1 PubMed Abstract | Publisher Full Text 2. Hunt LT, Woolrich MW, Rushworth MF, Behrens TE: Trial-type dependent frames of reference for value comparison.PLoS Comput Biol. 2013; 9 (9): e1003225 PubMed Abstract | Publisher Full Text 3. Muhammed K, Manohar S, Ben Yehuda M, Chong TT, et al.: Reward sensitivity deficits modulated by dopamine are associated with apathy in Parkinson's disease.Brain. 139 (Pt 10): 27062721 PubMed Abstract | Publisher Full Text

Is the work clearly and accurately presented and does it cite the current literature? Yes

Is the study design appropriate and is the work technically sound? Yes

Are sufficient details of methods and analysis provided to allow replication by others? Yes

If applicable, is the statistical analysis and its interpretation appropriate? Yes

Are all the source data underlying the results available to ensure full reproducibility? Partly

Are the conclusions drawn adequately supported by the results? Yes

Competing Interests: I was named as a collaborator on Tobias Hauser's Sir Henry Dale Fellowship 
(211155), but in practice we have not ended up collaborating on this work. I was in the same lab as Tobias from 2012-2017 at UCL before I returned to Oxford, and we co-authored a paper together during that time (2015), which led to him including me as a potential collaborator on his Dale application - but in the end we haven't worked together on any projects since then (although we are still in occasional contact).

Reviewer Expertise: Cognitive neuroscience of decision making

I confirm that I have read this submission and believe that I have an appropriate level of expertise to confirm that it is of an acceptable scientific standard.

Reviewer Report 10 February 2022

https://doi.org/10.21956/wellcomeopenres.19264.r48269

(C) 2022 Grüschow $\mathbf{M}$ et al. This is an open access peer review report distributed under the terms of the Creative Commons Attribution License, which permits unrestricted use, distribution, and reproduction in any medium, provided the original work is properly cited.

\section{Marcus Grüschow}

Zurich Center for Neuroeconomics (ZNE), Department of Economics, University of Zurich, Zurich, Switzerland

\section{Hui-Kuan Chung}

Zurich Center for Neuroeconomics (ZNE), Department of Economics, University of Zurich, Zurich, Switzerland

\section{Nikita Sidorenko}

Zurich Center for Neuroeconomics (ZNE), Department of Economics, University of Zurich, Zurich, Switzerland

Do propranolol and amisulpride modulate confidence in risk- taking? Johanna Habicht, Magda Dubois, Jochen Michely, Tobias U. Hauser

The authors assessed the contribution of noradrenaline and dopamine to value-based decision making and the subjective choice confidence using a monetary risky gambling task. No significant effect of either pharmacological manipulations on value-based decision making nor on subjective confidence was found. The main strength of the manuscript lies in its detailed reporting of all findings, investigation of effects added by covariates and the transparent reporting of null findings. However, the manuscript suffers from one major drawback - its generality. It does not offer anything new for the interested reader in terms of decision making, confidence or drug effects and this is not related to the null findings. Per se, absence of an effect is not uncommon for drug studies (Webber et al. 2021 ${ }^{1}$ ).

\section{Title and introduction}

1. The title and introduction are misleading and lack coherence with the analyses that are conducted. 
2. The introduction lacks literature about how different factors affect metacognition/confidence. Especially previous research in the field that has studied whether confidence reflects the posterior probability of the chosen option, total value of all options or the difference of values (e.g. Folke et al., 2016²; Li et al., 20203; Brus et al., 2021 ${ }^{4}$ ). Moreover, there is new evidence, showing that the confidence level relies on the amount the unchosen alternative has been taken into account before making the choice (Brus et al., 20214).

3. In general, the manuscript needs major expansion on the neuro-biological theory behind the behaviours studied, as well as the potential effects of the drugs used. Since many concepts have not been introduced enough and the manuscript is in fact bare of any hypotheses as to what might be observed, it seems very post hoc and exploratory.

4. Burke et $a l .2018^{5}$ for instance provided a comprehensive description of their rationale based on psychological and physiological mechanisms. For instance the authors could extend their motivation to investigate the role of dopamine and norepinephrine beyond the simple fact that metacognition is impaired in some disorders. For example, the authors mention the effect of amisulpride on receptors D2/D3 but do not explain their motivation for targeting these specific receptors and not, let's say, D1.

\section{Analysis}

1. The main downside of the analysis is that the authors didn't model the subjective value. This makes it difficult to compare to the previous studies cited in the paper (e.g. Hunt et al., 2013 ${ }^{6}$ and Burke et $a l ., 2018^{5}$ ). If the task is similar to the one in Hunt et al., $2013^{6}$ as described in the paper, it is not clear why the author didn't estimate subjective value and probability as done in Hunt et al., $2013^{6}$.

2. The analysis followed Hunt et al., $2013^{6}$ (e.g. testing probability difference), but it is not clear why those should also explain confidence. Also, as mentioned in the previous point, not just the difference, but the total value has also been studied. Why the author pick chosen value instead of total value?

3. It is surprise that the authors didn't test the reaction time effect on confidence since that is a robust result in previous studies (e.g. De Martino et al.,20137; Folke et al.,20162; da Silva Castanheira et al., 2021 ${ }^{8}$ ).

4. The authors mention they performed a logistic regression to predict choosing the option on the right side at every trial using reward magnitude, probability and EV as predictors. However, it remains unclear whether this is across both options, the sum, the difference, what?

5. The authors also mention to have examined whether catecholamines affect how the reward magnitude, probability and EV influence one's choice and compared the parameter estimates from the logistic regression between groups. Which groups exactly? Unclear? Please be precise in writing. It would be advantageous if the authors used mixed effect model approaches or any hierarchical model for data analysis.

6. 'Integrate across reward magnitude and probability to make optimal choices'. Notion of 
optimality is not appropriate here as the deviation from expected value maximization can be explained by individual risk attitudes. Please rephrase here and throughout the manuscript.

7. The authors administered their PANAS questionnaires only once, after the drug was received. How do they motivate the inclusion of PANAS scores in their ANCOVAs, if there is no comparison with individual baseline mood?

8. Did the authors somehow account for individual catecholamines baseline levels? If not, this should be discussed.

9. Because the task was distributed in varying delay (140 - 160 mins) and had an unrestricted response time, the drug effect might be also varying because of the duration from the drug administration to the time performing the task (even maybe in each trial). The reaction times are not reported so it is not clear if this might affect and if the model should include that factor.

10. We need to stress again, that an introduction and/or discussion of how these drugs could have impacted or have impacted in previous work the neurobiology of decision making is completely missing from the manuscript and would be an important piece for future researchers to find the relevant publication to derive useful hypotheses to test with appropriate paradigms.

\section{Discussion:}

1. Indicating that the task design was different between the current study and previous ones is important, however, it is not entirely clear how the authors link it to absence of an effect. It would be desirable, if the authors could elaborate on why and how having a dynamic task with included losses can affect the expression of drug effects.

2. The fourth paragraph of the discussion (about confidence) is simply a reframing of the Results section. The authors didn't provide any reason to support their results and didn't link their findings to previous research.

3. As it is written, it does not bring much novelty except detailed description of null results. To enrich the manuscript, the authors should carefully rewrite the discussion section and add much more neurophysiological detail. The results here need to be discussed in light of previous findings, potential hypothesis about null findings should be elaborated. The literature on dopamine and norepinephrine is extremely rich and full of null, confirmatory or contradicting findings, which makes it actually easy to relate the current findings to previous ones.

4. "Suggesting that dopamine and noradrenaline did not play a role in confidence in this task context". The authors obviously tried to make this statement as attenuated and cautious as possible, but it remains bold. To rule out the role of dopamine, one would need not only act on both striatum and prefrontal cortex but also have another group, where DA function would be enhanced. This is not the case in the present study, suggestion about dopamine (at least) not playing a role seems to be bold and needs rewriting.

5. Discussing the role of norepinephrine in processing uncertainty is not entirely appropriate 
in the context of the present task. Uncertainty is rather an umbrella term, and it would be desirable, if the authors could incorporate a discussion about the differences of noradrenergic effects on its components, namely risk and ambiguity, from previous studies. This point is important because the current task only contains a risk component because the odds of all options are well defined.

6. The authors suggest that the drugs effect could be explained (in part) by the difference in negative mood. Is it possible that the drugs induce that very same effect even before the tasks, when participants take the survey?

\section{For replication:}

1. We commend the authors for using a Bayesian approach for testing the null-model which is very useful here.

2. An important design feature that should be taken on for replication and/or future studies was that each item pairing was repeated twice (once in each spatial configuration), and therefore it was possible to examine choice consistency and confidence consistency.

3. For replication and/or optimization of future designs it would be good to report the distributions of task factors across all trials per person, such as magnitude, probability, EV (trial-wise sum and difference) as well as the subjective value distribution.

\section{Future suggestions}

1. Sample size was selected based on previous studies that used the same pharmacological manipulation (e.g. Dubois et al. $2021^{9}$ ). It would be advantageous to use power calculations for both within and between subject designs as it seems that $\mathrm{N}=19$ is fairly small compared to previous studies. See Webber et al. $2021^{1}$ for several examples.

2. Eye-tracking could have been advantageous in this study as gaze would have informed the confidence part and pupil dilation would have been a valuable marker to assess potential separable impact of these drugs on pupil dilation.

3. Each individual per group receives the same magnitude of drugs. It is potentially advantageous to make the amount of individually administered drugs dependent on body weight and or BMI.

\section{Minor points:}

1. The trials numbers are very uneven in reversal trials and repetition trials and the standard deviations seems not very similar (s.d $=18.54$ vs s.d. $=10.22$ ). Did the authors test the equal variance assumption for t-test?

2. Be precise in writing. Sentences like this are not very clear: 'These psychiatric disorders are often known to have disturbances in noradrenergic and dopaminergic systems'.

3. Page 5, left column: 'multiple' should be 'product'.

4. "We found that both predicted the confidence level" - as the authors didn't perform any outof-sample validation, the word "predicted" seems inappropriately used here. Please rephrase.

We hope the authors find our comments useful to improve the manuscript and inform future research in this direction. 
Hui-Kuan Chung, Nikita Sidorenko \& Marcus Grueschow

\section{References}

1. Webber HE, Lopez-Gamundi $\mathrm{P}$, Stamatovich $\mathrm{SN}$, de Wit $\mathrm{H}$, et al.: Using pharmacological manipulations to study the role of dopamine in human reward functioning: A review of studies in healthy adults.Neurosci Biobehav Rev. 120: 123-158 PubMed Abstract | Publisher Full Text 2. Folke T, Jacobsen C, Fleming S, De Martino B: Explicit representation of confidence informs future value-based decisions. Nature Human Behaviour. 2017; 1 (1). Publisher Full Text

3. $\mathrm{Li} \mathrm{H}$, Ma W: Confidence reports in decision-making with multiple alternatives violate the Bayesian confidence hypothesis. Nature Communications. 2020; 11 (1). Publisher Full Text 4. Brus J, Aebersold H, Grueschow M, Polania R: Sources of confidence in value-based choice. Nature Communications. 2021; 12 (1). Publisher Full Text

5. Burke CJ, Soutschek A, Weber S, Raja Beharelle A, et al.: Dopamine Receptor-Specific Contributions to the Computation of Value.Neuropsychopharmacology. 43 (6): 1415-1424 PubMed Abstract | Publisher Full Text

6. Hunt LT, Woolrich MW, Rushworth MF, Behrens TE: Trial-type dependent frames of reference for value comparison.PLoS Comput Biol. 2013; 9 (9): e1003225 PubMed Abstract | Publisher Full Text 7. De Martino B, Fleming SM, Garrett N, Dolan RJ: Confidence in value-based choice.Nat Neurosci. 2013; 16 (1): 105-10 PubMed Abstract | Publisher Full Text

8. da Silva Castanheira K, Fleming SM, Otto AR: Confidence in risky value-based choice.Psychon Bull Rev. 2021; 28 (3): 1021-1028 PubMed Abstract | Publisher Full Text

9. Dubois M, Habicht J, Michely J, Moran R, et al.: Human complex exploration strategies are enriched by noradrenaline-modulated heuristics. eLife. 2021; 10. Publisher Full Text

Is the work clearly and accurately presented and does it cite the current literature? Partly

Is the study design appropriate and is the work technically sound?

Partly

Are sufficient details of methods and analysis provided to allow replication by others? Partly

If applicable, is the statistical analysis and its interpretation appropriate? Partly

Are all the source data underlying the results available to ensure full reproducibility? Partly

Are the conclusions drawn adequately supported by the results? Partly

Competing Interests: No competing interests were disclosed.

Reviewer Expertise: Noradrenergic arousal, decision making, stress resilience 
We confirm that we have read this submission and believe that we have an appropriate level of expertise to confirm that it is of an acceptable scientific standard, however we have significant reservations, as outlined above. 